\title{
COMBINATORIAL AND GLOBAL OPTIMIZATION
}


SERIES ON APPLIED MATHEMATICS

Editor-in-Chief: Frank Hwang

Associate Editors-in-Chief: Zhong-ci Shi and U Rothblum

Vol. 1 International Conference on Scientific Computation eds. T. Chan and Z.-C. Shi

Vol. 2 Network Optimization Problems - Algorithms, Applications and Complexity eds. D.-Z. Du and P. M. Pandalos

Vol. 3 Combinatorial Group Testing and Its Applications by D.-Z. Du and F. K. Hwang

Vol. 4 Computation of Differential Equations and Dynamical Systems eds. K. Feng and Z.-C. Shi

Vol. 5 Numerical Mathematics eds. Z.-C. Shi and T. Ushijima

Vol. 6 Machine Proofs in Geometry by S.-C. Chou, X.-S. Gao and J.-Z. Zhang

Vol. 7 The Splitting Extrapolation Method by C. B. Liem, T. Lü and T. M. Shih

Vol. 8 Quaternary Codes by Z.-X. Wan

Vol. 9 Finite Element Methods for Integrodifferential Equations by C. M. Chen and T. M. Shih

Vol. 10 Statistical Quality Control - A Loss Minimization Approach by $D$. Trietsch

Vol. 11 The Mathematical Theory of Nonblocking Switching Networks by F. K. Hwang

Vol. 12 Combinatorial Group Testing and Its Applications (2nd Edition) by D.-Z. Du and F. K. Hwang

Vol. 13 Inverse Problems for Electrical Networks by E. B. Curtis and J. A. Morrow

Vol. 14 Combinatorial and Global Optimization eds. P. M. Pardalos, A. Migdalas and R. E. Burkard 


\section{Series on}

\section{Applied Mathematics}

\section{Volume 14}

\section{COMBINATORIAL AND \\ GLOBAL OPTIMIZATION}

\section{Editors}

\section{Panos M. Pardalos}

Department of Industrial Systems Engineering University of Florida, USA

\section{Athanasios Migdalas}

Department of Production Engineering and Management

Technical University of Crete, Greece

\section{Rainer E. Burkard}

Institute of Mathematics

Technical University of Graz, Austria 


\title{
Published by
}

World Scientific Publishing Co. Pte. Ltd.

P O Box 128, Farrer Road, Singapore 912805

USA office: Suite 1B, 1060 Main Street, River Edge, NJ 07661

UK office: 57 Shelton Street, Covent Garden, London WC2H 9HE

\author{
Library of Congress Cataloging-in-Publication Data \\ Combinatorial and global optimization / editors Panos M. Pardalos, Athanasios \\ Migdalas, Rainer E. Burkard. \\ p. cm. - (Series on applied mathematics ; v. 14) \\ Includes bibliographical references. \\ ISBN 9810248024 (alk. paper) \\ 1. Combinatorial optimization -- Congresses. 2. Mathematical \\ optimization--Congresses. 3. Nonlinear programming--Congresses. I. Pardalos, P. M. \\ (Panos M.), 1954- II. Migdalas, Athanasios. III. Burkard, Rainer E. IV. Series.
}

QA402.5.C5435 2001

$511^{\prime} \cdot 6-\mathrm{dc} 21$

\section{British Library Cataloguing-in-Publication Data}

A catalogue record for this book is available from the British Library.

Copyright $\odot 2002$ by World Scientific Publishing Co. Pte. Ltd.

All rights reserved. This book, or parts thereof, may not be reproduced in any form or by any means, electronic or mechanical, including photocopying, recording or any information storage and retrieval system now known or to be invented, without written permission from the Publisher.

For photocopying of material in this volume, please pay a copying fee through the Copyright Clearance Center, Inc., 222 Rosewood Drive, Danvers, MA 01923, USA. In this case permission to photocopy is not required from the publisher. 


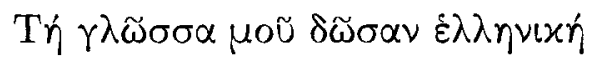

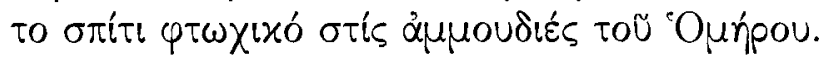

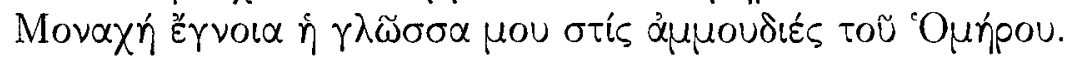

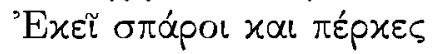

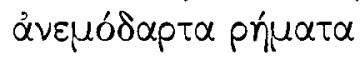

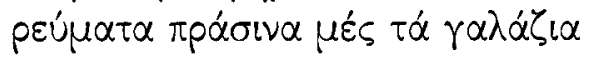

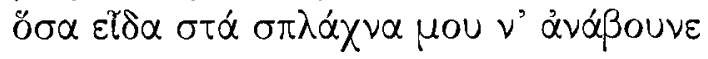

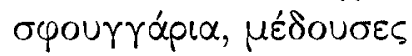

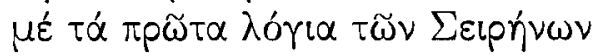

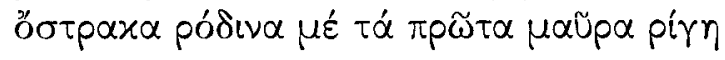

I was given the Hellenic tongue

my house a humble one on the sandy shores of Homer.

My only care my tongue on the sandy shores of Homer.

The sea-bream and perch

windbeaten verbs

green currents with the cerulean

all that I saw blazing in my entrails

sponges, medusae

with the first words of the Sirens

pink shells with their first dark tremors

(from Axion Esti, 1959) - Odysseas Elytis 


\title{
Preface
}

Combinatorial and global optimization problems appear in a wide range of applications in operations research, engineering, biological sciences and computer science. In combinatorial optimization and graph theory many approaches have been developed that link the discrete universe to the continuous universe through geometric, analytic, and algebraic techniques. Such techniques include global optimization formulations, semidefinite programming, and spectral theory. Major recent successes based on these approaches include interior point algorithms for linear and discrete problems, the celebrated Goemans-Williamson Relaxation of the maximum cut problem, and the Du-Hwang solution of the Gilbert-Pollak's Conjecture. Since integer constraints are equivalent to nonconvex constraints, the fundamental difference between classes of optimization problems is not between discrete and continuous problems but between convex and nonconvex optimization problems.

A conference on Combinatorial and Global Optimization was held at Chania, Crete, Greece. The conference was sponsored by the Center of Applied Optimization of the University of Florida, USA, and the Center for Information Technology Transfer (CENIIT) of Linköping Institute of Technology in Sweden. The conference provided a forum for researchers working on different aspects of combinatorial and global optimization to present their recent discoveries, and to interact with people working on complementary aspects of mathematical programming. This volume contains a selective collection of refereed papers based on talks presented at the conference.

We would like to take the opportunity to thank the sponsors, the program committee members, the authors of the papers, the anonymous referees, and World Scientific for making the conference successful and the publication of this interesting book possible.

\author{
P. M. Pardalos, A. Migdalas, and R. E. Burkard \\ Chania, Crete \\ May 2001
}


This page is intentionally left blank 


\section{Contents}

Preface vii

A Forest Exterior Point Algorithm for Assignment Problems 1

H. Achatz, K. Paparrizos, N. Samaras, and K. Tsiplidis

1 Introduction . . . . . . . . . . . . . . . . . 2

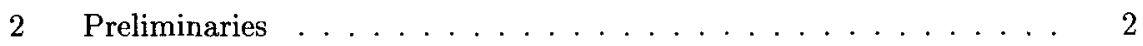

3 Description of the algorithm ................. 3

4 Correctness and complexity of the algorithm . . . . . . . . . . 5

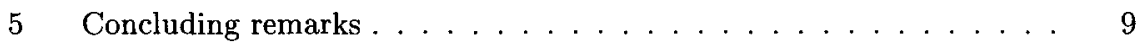

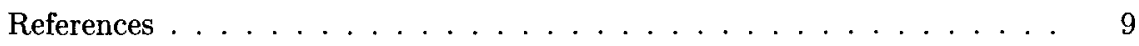

A Hybrid Scatter Genetic Tabu Approach for Continuous Global Optimization

I. M. Al-Harkan and T. B. Trafalis

1 Introduction . . . . . . . . . . . . . . . . 12

2 Genetic, scatter search and tabu serach approach ......... 13

3 HSGT algorithm description . . . . . . . . . . . . . 16

4 Weight computations ................... 18

5 Computational results ................... . . 20

6 Conclusions and recommendations . . . . . . . . . . . . . . 21

Appendix A: Test functions . . . . . . . . . . . . . . . . . 22

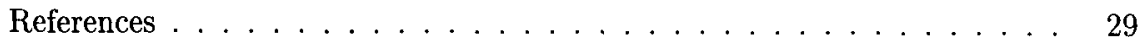


Exact Rates of Prokhorov Convergence under Three Moment Conditions

G. A. Anastassiou and T. Rychlik

1 Main result . . . . . . . . . . . . . . . . . . 34

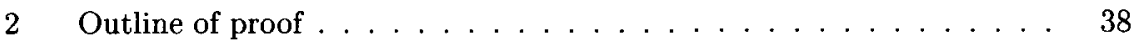

References . . . . . . . . . . . . . . . . . . . . 42

Location/Allocation of Queuing Facilities in Continuous Space using Minsum and Minimax Criteria

J. Brimberg, R. F. Love and A. Mehrez

1 Introduction . . . . . . . . . . . . . . . . . 44

2 The model . . . . . . . . . . . . . . . . . . . . 45

3 A solution method .................... . . 48

4 Computational results $\ldots \ldots \ldots \ldots \ldots$

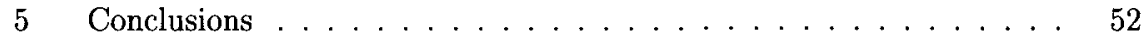

References .......................... 52

Algorithms for the Consistency Analysis in Scenario Projects $\quad 55$

R. Feldmann, N. Sensen, B. Monien, and O. Schlake

1 Introduction . . . . . . . . . . . . . . . . 56

2 Definitions . . . . . . . . . . . . . . . . . 58

$3 \quad$ Complexity . . . . . . . . . . . . . . . . . . . 59

4 Algorithms . . . . . . . . . . . . . . . . . . 63

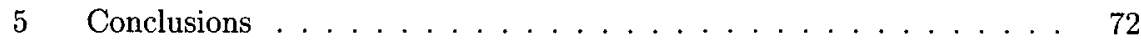

References ........................ 72

Assignment of Reusable and Non-Reusable Frequencies $\quad 75$

D. A. Fotakis and P. G. Spirakis

1 Introduction . . . . . . . . . . . . . . . 76 


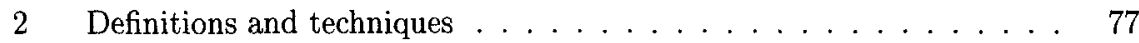

3 The complexity of radio coloring and radio labelling . . . . . . . . 81

4 An exact algorithm for constant number of colors . . . . . . . . . 84

5 Algorithms for on-line radio labelling . . . . . . . . . . . . 90

6 Open problems $\ldots \ldots \ldots \ldots \ldots$

References . . . . . . . . . . . . . . . . . . . . . 94

Image Space Analysis for Vector Optimization and Variational Inequalities. Scalarization

F. Giannessi and L. Pellegrini

$1 \quad$ Introduction . . . . . . . . . . . . . . . . . . . . 98

2 A separation scheme . . . . . . . . . . . . . . . . . 99

3 On the scalarization of vector optimization . . . . . . . . . 101

4 Vector variational inequalities . . . . . . . . . . 105

References . . . . . . . . . . . . . . . . . . . . 108

Solving Quadratic Knapsack Problems by Reformulation and Tabu Search. Single Constraint Case

F. Glover, G. Kochenberger, B. Alidaee and M. Amini

1 Introduction . . . . . . . . . . . . . . . . . . . 112

2 Reformulation ....................... 113

3 Computational experiments . . . . . . . . . . . . . 115

4 Summary and conclusions . . . . . . . . . . . . . . . . 119

Appendix: Overview of our tabu search algorithm . . . . . . . . . 120

References . . . . . . . . . . . . . . . . . . . 120

Global Optimization using Dynamic Search Trajectories $\quad 123$

A. A. Groenwold and J. A. Snyman

1 Introduction . . . . . . . . . . . . . . . . . . . . . . . . 124 
2 The Snyman-Fatti trajectory method . . . . . . . . . . . 125

3 The modified bouncing ball trajectory method . . . . . . . . . 127

4 Global stopping criterion . . . . . . . . . . . . . . . 128

$5 \quad$ Numerical results . . . . . . . . . . . . . . . . . . . . . . . . . 129

6 Conclusions . . . . . . . . . . . . . . . . . 131

References .......................... 131

On Pareto Efficiency. A General Constructive Existence Principle 133 G. Isac

1 Introduction . . . . . . . . . . . . . 133

2 Preliminaries . . . . . . . . . . . . . . . 135

3 The main result $\ldots \ldots \ldots \ldots \ldots \ldots$

4 Realizations of Theorem $1 \ldots \ldots \ldots$. . . . . . . . . . . . .

References . . . . . . . . . . . . . . . . . . . 142

$\begin{array}{lr}\text { Piecewise Linear Network Flow Problems } & 145\end{array}$

D. Kim and P. M. Pardalos

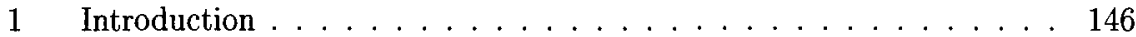

2 Applications . . . . . . . . . . . . . . . 156

3 Concluding remarks . . . . . . . . . . . . . . . . 157

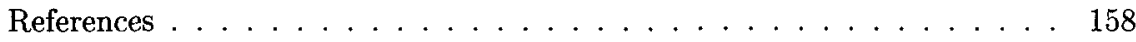

Semidefinite Programming Approaches for MAX-2-SAT and MAX-3SAT: computational perspectives

E. de Klerk and J. P. Warners

1 Introduction . . . . . . . . . . . . . . . . . 162

2 The SDP relaxation of MAX-2-SAT . . . . . . . . . . . . . 162

3 Additional valid inequalities . . . . . . . . . . . . . . 165 
4 Solving the SDP relaxation of MAX-2-SAT . . . . . . . . . 166

5 A branch and cut framework .................... 168

6 Numerical experiments . . . . . . . . . . . . . . . 171

$7 \quad$ Future work . . . . . . . . . . . . . . 172

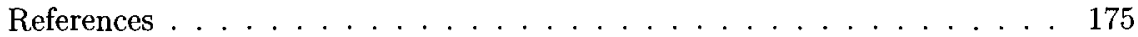

On a Data Structure in a Global Description of Sequences $\quad 177$

V. Korotkich

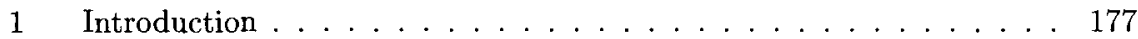

2 Structural numbers and their geometric interpretation . . . . . . . 179

3 Structural numbers as coordinates of a space and a system of linear equations ..................... 181

4 Integer patterns: Means for the visualization of the system . . . . . 185

5 What picture appears when the system is visualized: An illustrative example ................... . 186

6 Definition of the structure and its isomorphic representations: Web of relations . . . . . . . . . . . . . . . . . 191

7 On descriptive potentialities of the structure: Simple examples of global

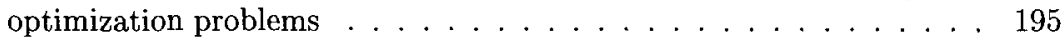

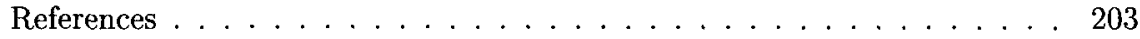

Heuristic Solutions of Vehicle Routing Problems in Supply Chain Management

Y. Marinakis and A. Migdalas

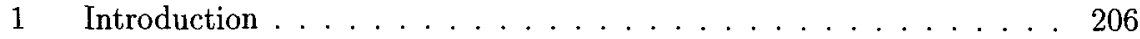

2 Supply chain management ................. 206

3 The vehicle routing problem ................ 207

4 Classic heuristics for the traveling salesman and the vehicle routing problems ..................... 210 
xiv

$5 \quad$ Metaheuristics for the traveling salesman and the vehicle routing problems 219

6 Computational results . . . . . . . . . . . . . 228

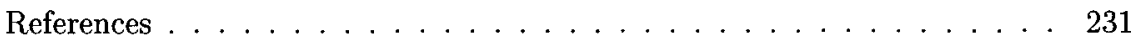

A New Finite Cone Covering Algorithm for Concave Minimization

C. Meyer and B. Jaumard

1 Introduction . . . . . . . . . . . . . . 238

2 Basic operations ..................... 239

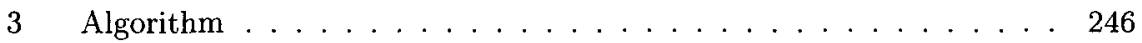

4 Conclusions ...................... 247

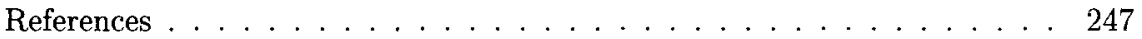

A Diagonal Global Optimization Method 251

A. Molinaro, C. Pizzuti and Y. D. Sergeyev

1 Introduction . . . . . . . . . . . . . . 252

2 Diagonal information global optimization algorithm and its new convergence conditions ................... 253

3 A new diagonal information algorithm . . . . . . . . . . 256

4 Numerical results . . . . . . . . . . . . . . . . . 258

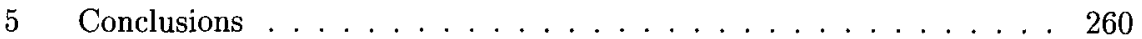

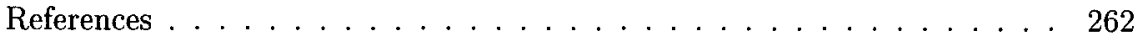

Frequency Assignment for Very Large, Sparse Networks 265

R. Murphey

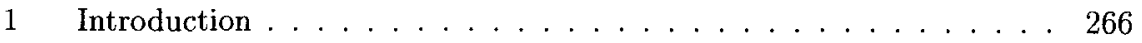

2 Minimum order and minimum span assignments . . . . . . . . . . 267

3 Alternate graph approach ................. 272

4 Local search . . . . . . . . . . . . . . . 275 
$5 \quad$ Experimental results $\ldots \ldots \ldots \ldots \ldots \ldots \ldots$

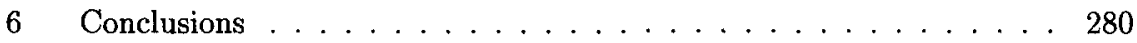

References . . . . . . . . . . . . . . . . . . 280

A Derivative Free Minimization Method for Noisy Functions 283

V.P. Plagianakos and M. N. Vrahatis

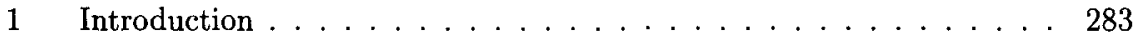

2 Optimization of noisy functions . . . . . . . . . . . . 284

3 A derivative-free minimization method for imprecise problems and its

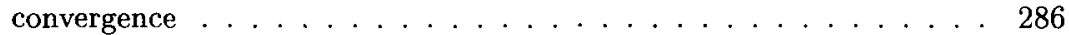

4 Numerical applications . . . . . . . . . . . . . . . . 289

$5 \quad$ Concluding remarks . . . . . . . . . . . . . . 293

References . . . . . . . . . . . . . . . . . . . . . 294

$\begin{array}{ll}\text { Tight QAP Bounds via Linear Programming } & 297\end{array}$

K. G. Ramakrishnan, M. G. C. Resende, B. Ramachandran and J. F. Pekny

1 LP-based lower bounds for the QAP . . . . . . . . . . . 298

2 Experimental results . . . . . . . . . . . . . . . . . 299

3 Concluding remarks . . . . . . . . . . . . . . . . 301

References . . . . . . . . . . . . . . . . . . 302

GPS Network Design: An Application of the Simulated Annealing Heuristic Technique

H. A. Saleh and P. J. Dare

1 Introduction . . . . . . . . . . . . . . 306

2 Simulated annealing technique . . . . . . . . . . . 307

3 Formulation of the GPS surveying problem . . . . . . . . 307

4 The GPS-simulated annealing algorithm . . . . . . . . . . . . 309

5 Computational results $\ldots \ldots \ldots . \ldots \ldots$ 
xvi

6 Further work and conclusion . . . . . . . . . . . . . 310

References ........................ . . 311

Global Optimization for Crack Identification:Impact-Echo Experiments 317

G. E. Stavroulakis

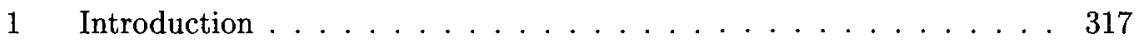

2 Global optimization for inverse problems . . . . . . . . . . . 319

3 Mechanical modelling . . . . . . . . . . . . . . . . 320

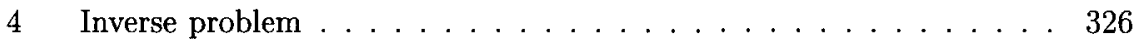

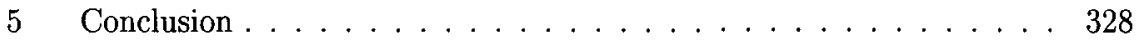

References . . . . . . . . . . . . . . . . . . . 329

Normal Branch and Bound Algorithms for General Nonconvex Quadratic

Programming

H. Tuy

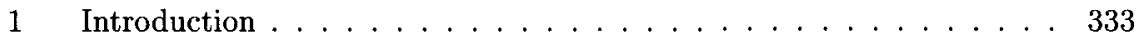

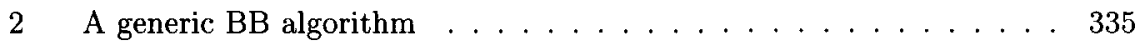

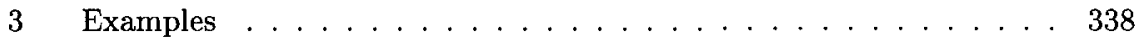

4 Quadratic system equivalent to a linear system . . . . . . . . . . . 340

5 General decoupling scheme . . . . . . . . . . . . . . . . . . 344

$6 \quad$ Linear relaxations . . . . . . . . . . . . . . . . . . . . 345

$7 \quad$ Semidefinite relaxation $\ldots \ldots \ldots \ldots$

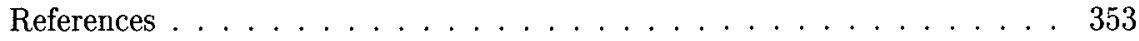

